\title{
Reproducibility of left atrial ablation with high-intensity focused ultrasound energy in a calf model
}

\author{
Nestor R. Villamizar, MD, ${ }^{\mathrm{a}}$ Jennifer H. Crow, MD, ${ }^{\mathrm{b}}$ Valentino Piacentino III, MD, PhD, ${ }^{\mathrm{a}}$ \\ Louis R. DiBernardo, MD, ${ }^{\mathrm{b}}$ Mani A. Daneshmand, MD, ${ }^{\mathrm{a}}$ Dawn E. Bowles, PhD, ${ }^{\mathrm{a}}$ Mark A. Groh, MD, ${ }^{\mathrm{c}}$ and \\ Carmelo A. Milano, MD $^{\mathrm{a}}$
}

\begin{abstract}
Objective: Achieving transmural tissue ablation might be necessary for successful treatment of atrial fibrillation. The purpose of this study was to evaluate the reproducibility of transmural left atrial ablation using a high-intensity focused ultrasound energy system in a calf model.
\end{abstract}

\begin{abstract}
Methods: Nine heparinized bovines underwent a beating-heart left atrial ablation with a single application of the high-intensity focused ultrasound device. All animals were acutely killed, and the left atrium was fixed in formalin. Protocolized histological sections $(5 \mu \mathrm{m})$ were obtained throughout each lesion and prepared with Masson trichrome and hematoxylin and eosin staining. Measurements were performed on a total of 359 slides from the 9 lesions. In addition, fresh left atrial tissues from 18 unused human donor hearts that did not meet the criteria for cardiac transplantation were measured at the site where the high-intensity focused ultrasound device is normally applied.
\end{abstract}

Results: Calf left atrial thickness ranged between 2.5 and $20.1 \mathrm{~mm}$, with a mean of $9.10 \mathrm{~mm}$. High-intensity focused ultrasound ablation consistently produced a $100 \%$ transmural lesion in left atrial thickness up to $6 \mathrm{~mm}$. In addition, a transmural lesion was observed in $91 \%$ of tissues that were up to $10 \mathrm{~mm}$ thick and in $85 \%$ that were up to $15 \mathrm{~mm}$ thick. Human left atrial thickness ranged between 1.2 to $6 \mathrm{~mm}$, with a mean of $3.7 \mathrm{~mm}$.

Conclusions: Calf left atrial thickness in this study was greater than human left atrial thickness. Human left atrial thickness is generally less than $6 \mathrm{~mm}$, and in this range high-intensity focused ultrasound ablation achieved $100 \%$ transmurality. These histological results might correlate with a high success rate of atrial fibrillation ablation by using the high-intensity focused ultrasound system. (J Thorac Cardiovasc Surg 2010;140:1381-7)

\section{Supplemental material is available online.}

Atrial fibrillation (AF) is present in approximately $9 \%$ of patients older than 70 years and has been recognized as an independent risk factor for cardiovascular morbidity and mortality. ${ }^{1}$ Reported freedom from AF with medical management and catheter ablation techniques is inferior to the cut-and-sew Cox maze III procedure, which con-

\footnotetext{
From the Departments of Surgery ${ }^{\mathrm{a}}$ and Pathology, ${ }^{\mathrm{b}}$ Duke University Medical Center, Durham, NC; and Mission Saint Joseph Hospital, ${ }^{\mathrm{c}}$ Asheville, NC.

This work was supported in part by an unrestricted grant from St Jude Medical and National Institutes of Health grant no. P01-HL075443 to Dr Milano.

Disclosures: Dr Mark Groh is a consultant to the Atrial Fibrillation Division of St Jude Medical.

Read at the 36th Annual Meeting of The Western Thoracic Surgical Association, Ojai, Calif, June 23-26, 2010.

Received for publication June 18, 2010; revisions received Aug 3, 2010; accepted for publication Aug 13, 2010; available ahead of print Oct 11, 2010.

Address for reprints: Nestor R. Villamizar, MD, Duke University Medical Center, 4024 S Roxboro St, Unit 121, Durham, NC 27713 (E-mail: villa022@mc.duke. edu).

0022-5223/\$36.00

Copyright (C) 2010 by The American Association for Thoracic Surgery

doi:10.1016/j.jtcvs.2010.08.029
}

tinues to be the gold standard for the treatment of $\mathrm{AF}$, with $92 \%$ to $97 \%$ cure rates at 10 years of follow-up. ${ }^{2}$ However, this procedure has not been widely adopted because of its technical complexity and because of the required additional cardiopulmonary bypass time. The identification of trigger zones for $\mathrm{AF}^{3}$ specifically around the pulmonary vein orifices, has lead to the development of simpler, less invasive procedures using different energy sources. Several different energy sources applied endocardially, epicardially, or both have been used for this purpose with variable results. A common goal when developing new technologies for atrial ablation has been to create transmural lesions similar to what is obtained with the cut-and-sew Cox maze procedure. Some of the challenges that these new technologies need to overcome include the ability to ensure transmurality without damage of the surrounding structures in the setting of variations in thickness, fat content, and the cooling effect of atrial blood flow. High-intensity focused ultrasound (HIFU) is a young technology in the armamentarium for AF ablation. Clinical trials performed in Europe ${ }^{4}$ and the United States ${ }^{5}$ with HIFU in patients with AF undergoing concomitant cardiac surgery have reported a rate of freedom from $\mathrm{AF}$ of $85 \%$ at 18 months of follow-up. However, a histological analysis demonstrating the presence of transmural 


\section{Abbreviations and Acronyms \\ $\mathrm{AF} \quad=$ atrial fibrillation \\ HIFU $=$ high-intensity focused ultrasound \\ LA $=$ left atrium}

lesions with HIFU had not yet been published. The purpose of this study was to assess the safety and reproducibility of transmural left atrial (LA) ablation with the Epicor LP HIFU system (St Jude Medical, St Paul, Minn) in a calf model.

\section{MATERIALS AND METHODS Device Description}

The Epicor Cardiac Ablation System has been previously described. ${ }^{4}$ Briefly, the system consists of the Ablation Control System generator, a family of disposable ablation devices, and a set of accessories. The Ablation Control System is a microprocessor-based unit that enables acoustic power to be delivered to the heart from ultrasound transducers. The UltraCinch LP device is an array of multiple (7-13) ultrasound transducers (cells) that is used to produce a transmural circumferential LA lesion, isolating the posterior LA and all 4 pulmonary vein orifices. An additional tool, the UltraWand LP, is a handheld ablation device with only 2 transducers for the epicardial creation of additional linear lesions, such as the line to the mitral annulus. The UltraWand LP was used in this model to assess the effect of HIFU energy applied over coronary vessels.

\section{Animal Studies}

The study was conducted at Duke University under approval of the Institutional Animal Care and Use Committee. All animals received humane care in compliance with the "Guide for the care and use of laboratory animals." Nine calves with a weight range of 63 to $114 \mathrm{~kg}$ were selected for the study.

\section{System Characteristics}

The transducers comprising the UltraCinch LP are positioned on the epicardium but separated from direct contact with the cardiac tissue by a thin perforated membrane. Room temperature normal saline is circulated between the membrane and the transducers during ablation to enhance acoustic coupling and cooling. Each transducer $(10 \times 15 \mathrm{~mm})$ is designed to deliver HIFU energy up to a distance of $10 \mathrm{~mm}$ from its surface. Beyond the focal point, the energy dissipates within the LA cavity without exposing the surrounding structures to potential collateral damage. The proprietary UltraCinch LP algorithm generated by the Ablation Control System uses a combination of frequency, power, and duration at which the transducers are activated and powered (from 3.8-6.4 MHz and from 15-130 W) to generate 3 sequential stages of ablation. The ablation process begins with the deep ablation stage, during which the energy is deposited distally from the transducer in the subendocardial zone, followed by the intermediate stage in which energy is deposited in the midmyocardial layer, followed by the surface stage for epicardial energy deposition. During the first 2 stages, each transducer is activated sequentially, and the energy is pulsed, whereas during the third stage, transducers are staged 3 at a time with continuouswave HIFU to eliminate any residual gap within the epicardium. The lesion is thus built up from the endocardium back to the epicardium and is complete within approximately 10 minutes. The UltraWand LP is activated in a similar fashion but uses a single stage for the creation of linear lesions during a shorter 80 -second algorithm that was designed for a handheld device.

\section{Surgical Technique}

The animals were anesthetized with isoflurane, and a median sternotomy was performed. The surgical ablation was executed as previously described by Ninet and colleagues. ${ }^{4}$ The pericardium was opened, and the pericardial reflections around both the superior vena cava and inferior vena cava were dissected free to gain access to both the transverse and oblique sinuses. A specially designed introducer sizer was passed behind the superior vena cava into the transverse sinus and guided into the oblique sinus and beneath the inferior vena cava, thereby completely encircling all 4 pulmonary veins. The graduated introducer sizer was used to measure the circumference of the LA to select the proper size of UltraCinch LP device. The introducer was subsequently used to guide the UltraCinch LP around the LA. The introducer was then removed, and the 2 ends of the UltraCinch LP device were approximated with tourniquets placed on the appropriate sutures at each end to snug the device securely around the LA (Figure 1, A).A 7- or 8-cell Epicor UltraCinch LP device was used in all 7 cases. A bolus of heparin $(100 \mathrm{IU} / \mathrm{kg})$ was administered before the ablation cycle start, and a continuous saline infusion was set by gravity with a bag height of 35 inches, which yields approximately $1.5 \mathrm{~mL} / \mathrm{min}$ per cell of irrigation into the membranes overlying the transducer cells. The ablation cycle was then initiated and progressed automatically until the UltraCinch LP ablation had been completed. Physiologic data were recorded during the ablation run. An additional lesion placed over the coronary sinus was also created epicardially with the UltraWand LP (Figure 1,B). A continuous saline infusion was maintained at a rate of $120 \mathrm{~mL} / \mathrm{h}$ during the UltraWand LP ablation cycle.

\section{Tissue Processing}

All animals were killed at the end of the procedure, and the heart was immediately explanted for macroscopic examination. The LA and additional cardiac tissue surrounding the UltraCinch LP and UltraWand LP lesions was widely resected en block. Endocardial and epicardial surfaces
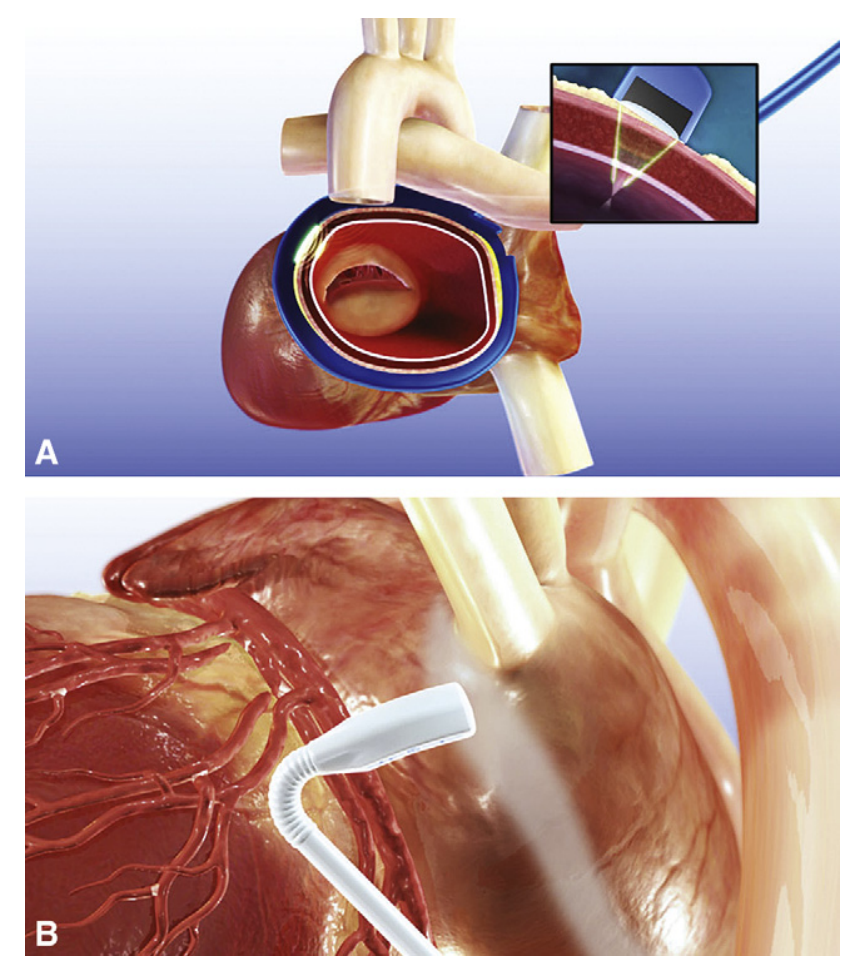

FIGURE 1. Sites of high-intensity focused ultrasound ablation. A, Position of the Epicor UltraCinch LP. B, Position of the Epicor UltraWand LP. 
were examined for color, appearance, evidence of perforation or rupture, presence of intramural hemorrhage, presence of endocardial thrombus, integrity of the pulmonary vein wall, and the mitral valve apparatus. The resected tissue was then fixed in $10 \%$ formalin until sectioning. The fixed LA was radially sectioned into 8 blocks, approximately equivalent to the locations of the individual device cells (see Figure E1). The wand lesion was serially sectioned perpendicular to the coronary sinus. Five standard $5-\mu \mathrm{m}$ sections were prepared from each block, alternating Masson trichrome and hematoxylin and eosin staining, and additional sections were prepared in the same manner until each block was completely sectioned. All sections were examined, and measurements were taken from 2 separate sections of each block by using an ocular micrometer.

\section{Measurements}

Measurements were obtained from a total of 359 slides. Tissue thickness was measured at the site of the lesion. Lesion thickness was measured. In addition, fat and myocardial thickness, which composed the lesion, was recorded. Lastly, any gap of uninjured tissue was measured. Lesion transmurality was calculated by comparing lesion depth and total tissue thickness, as shown in Figure 2.

\section{Human Studies}

Human hearts that did not meet criteria for cardiac transplantation were procured after research consent was obtained from our local organprocurement organization. Hearts were procured in standard fashion from donors in which the lungs were also not used for transplantation to allow for dissection and isolation of 2 to $3 \mathrm{~cm}$ of each pulmonary vein. The LA was separated from the left ventricle at the atrioventricular groove immediately above the mitral valve similar to the procurement of the bovine LAs. Measurements were made with a micrometer adjacent to but 2 $\mathrm{mm}$ central to each of the 4 pulmonary veins in the perceived location of the UltraCinch LP device. Three measurements were taken at each location and averaged. Data are presented as means \pm standard errors of the mean.

\section{RESULTS}

\section{Animal Studies}

Macroscopic examination. There was no evidence of perforation or rupture of the cardiac tissues subjected to ablation in any of the 9 animals. Gross examination of the UltraCinch LP application site revealed a wide, distinct,

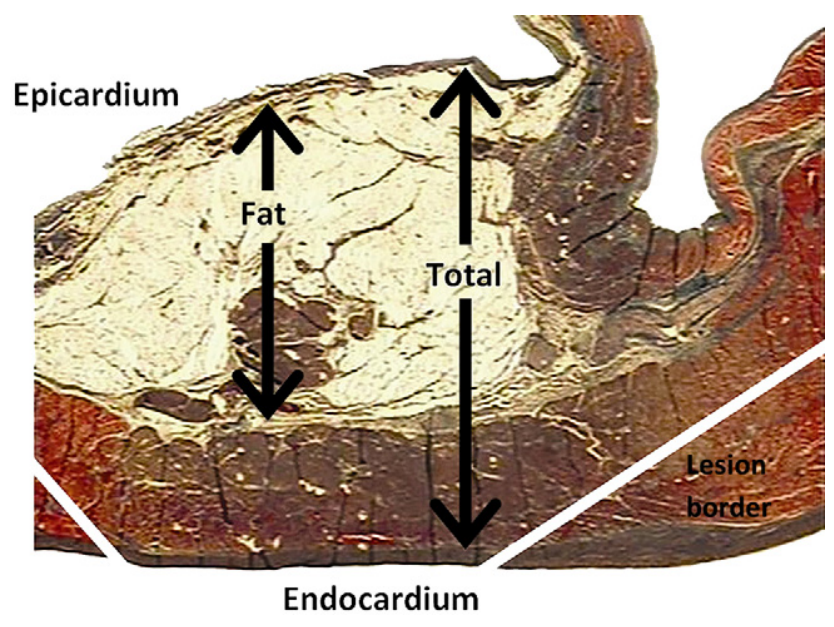

FIGURE 2. Histology of the high-intensity focused ultrasound lesion with total versus fat thickness measurement. circumferential lesion on the epicardium with corresponding linear tracts on the endocardial surface on inversion of the specimen, indicating transmural penetration of the lesion (Figure 3, A). Importantly, there was no evidence of LA endocardial injury distant to the lesion. No intramural hemorrhage or endocardial thrombus was identified in any of the 9 animals. The pulmonary vein wall and mitral valve apparatus demonstrated freedom from any injury in all 9 animals. Gross examination of the UltraWand LP application site did not show evidence of acute cavitation, perforation, thrombosis of epicardial coronary vessels, or other unintended trauma to the target tissue.

Microscopic examination. Microscopically, the type of injury caused by the Epicor UltraCinch LP device was characterized by a wedge-shaped lesion with a wide base at the epicardial surface that progressively narrowed to the endocardial surface. The histologic features include edema, nuclear hyperchromasia, and contraction bands, which are typical of irreversible myocardial injury (Figure 3,B).

Calf total LA thickness for all 359 slides ranged between 2.5 and $20.1 \mathrm{~mm}$, with a mean of $9.10 \mathrm{~mm}$. Adipose tissue thickness at the lesion site ranged between 0 and $16 \mathrm{~mm}$,

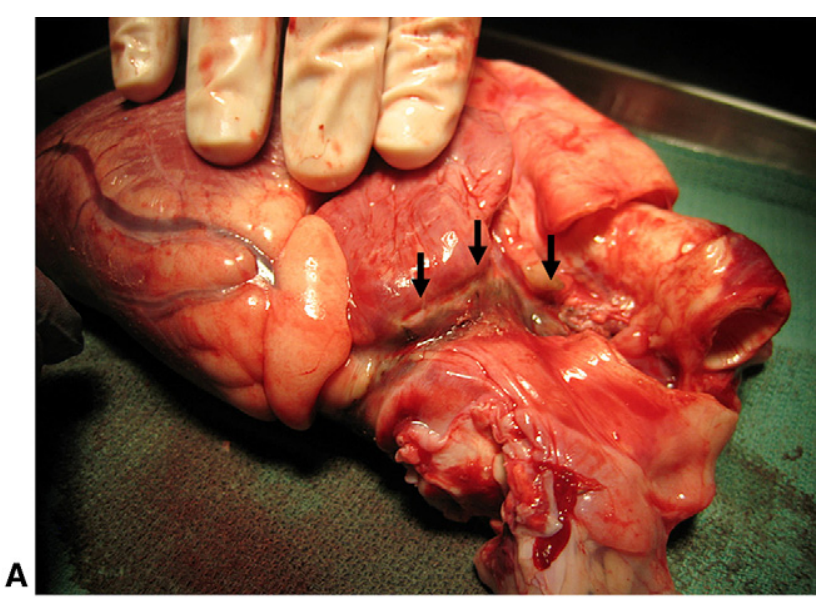

A

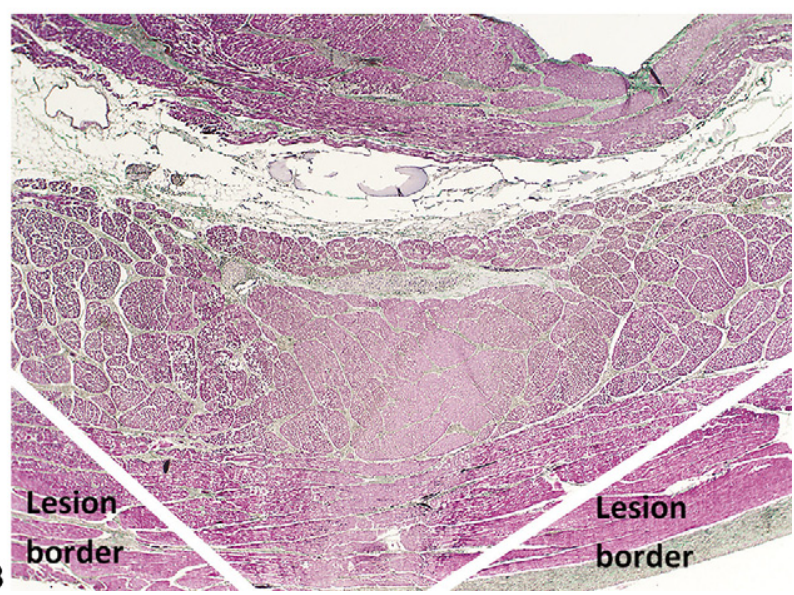

FIGURE 3. Characteristics of Epicor UltraCinch LP ablation. A, Macroscopic examination. B, Microscopic examination. 


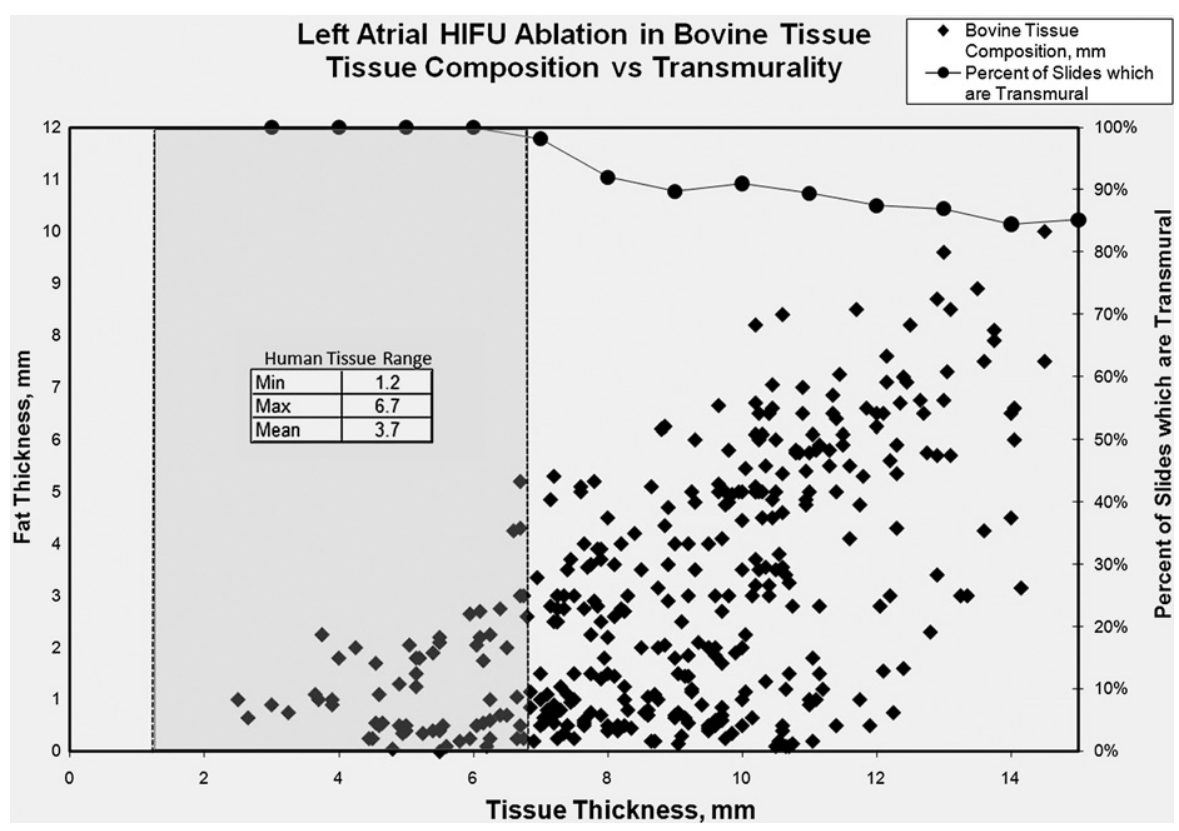

FIGURE 4. Percentage of transmural lesions in relation to distribution of total thickness and percentage of adipose tissue using the Epicor UltraCinch LP. $H I F U$, High-intensity focused ultrasound.

with a mean of $3.10 \mathrm{~mm}$. The distribution of total thickness and percentage of adipose tissue for the entire cohort is represented in Figure 4. Seventy-one percent of the measured slides contained LA tissue that was $10 \mathrm{~mm}$ or less in total thickness, which is the greatest depth at which the HIFU beam is focused.

The Epicor UltraCinch LP consistently produced a 100\% transmural lesion in LA thickness up to $6 \mathrm{~mm}$, which includes adipose tissue of up to $2.7 \mathrm{~mm}$. In addition, a transmural lesion was observed in $91 \%$ of tissues that were up to 10 $\mathrm{mm}$ thick and in $85 \%$ of tissues that were up to $15 \mathrm{~mm}$ thick (Figure 4). The greatest total tissue thickness that underwent a $100 \%$ transmural lesion was $14.5 \mathrm{~mm}$. The greatest total adipose tissue that underwent a $100 \%$ transmural lesion was $9.6 \mathrm{~mm}$. Nontransmural lesions were not located at a defined anatomic landmark in every animal nor was there a correlation between nontransmural lesions and the cell number within the Epicor UltraCinch LP. The amount of adipose tissue present on the target LA did not appear to correlate with lesion transmularity. In contrast, the shape of the target tissue and the orientation of the HIFU lesion (the direction of the wedge-shaped lesion) seemed to play an important role in obtaining transmurality (see Figure E2).

All nerve bundles identified within the HIFU beam appeared irreversibly injured independent of size or tissue depth (see Figure E3).

The Epicor UltraWand LP lesion was microscopically similar to the UltraCinch LP lesion. No thrombosis was seen inside the coronary sinus or circumflex artery over which the Epicor UltraWand LP was applied. However, there is some evidence of insult to smaller vessels that cannot be fully characterized. The endothelial cell nuclei are rounded, enlarged, and protrude into the lumen; these are characteristic features of injured or reactive endothelial cells. There are no specific histologic features that allow differentiation between reversible versus irreversible endothelial cell injury. It should be noted that no injury to the circumflex artery or other nearby vessels has been observed in chronic human studies extending as far out as 18 months after the procedure. ${ }^{5,6}$

\section{Human Studies}

To determine the relationship of the calf model to adult human LA thickness, we also measured LA thickness in 18 adult human unused donor hearts. The average age of hearts examined was $51.8 \pm 4.6$ years, and $28 \%$ had a history of cardiovascular disease. The mean human LA thickness was $3.7 \mathrm{~mm}$, with a range of $1.2 \mathrm{~mm}$ to a maximum thickness of $6 \mathrm{~mm}$.

\section{DISCUSSION}

AF is a significant cause of cardiovascular morbidity and mortality. ${ }^{1}$ The success rate of medical therapy and catheter ablation remains suboptimal. The cut-and-sew Cox maze III surgical procedure has proved to be very effective but still carries a significant risk for complications and is technically challenging. ${ }^{2}$ The development of new technologies to reproduce the outcomes obtained with the Cox maze III procedure but to minimize risks is an area of active investigation. Alternative energy sources used to treat $\mathrm{AF}$ include hypothermic sources (cryoablation) and hyperthermic sources (radiofrequency, microwave, laser, and ultrasound ablation). 
Since Haissaguerre and colleagues ${ }^{3}$ identified the pulmonary vein orifices as the trigger zones for $\mathrm{AF}$, a great interest has emerged to design ablation devices capable of isolating these trigger zones. The Epicor LP HIFU system has been designed to electrically isolate these areas in a safe and reproducible manner.

Although the necessity to achieve conduction block acutely is still a debatable topic, mature transmural lesions will always result in chronic electrical block. Accordingly, the only guarantee of long-term effectiveness is a fully transmural lesion. For instance, Melby and associates ${ }^{6}$ have shown that AF can conduct through gaps of $1 \mathrm{~mm}$ or greater in ablation lines. Furthermore, gaps along the lines of prior ablation have been identified in patients with unsuccessful surgical ablation. ${ }^{7}$ One of the end points of this study was to determine the presence of transmurality in the ablations created with the Epicor LP HIFU system. A single epicardial, beating-heart application of the Epicor UltraCinch LP device was $100 \%$ effective in producing a transmural lesion in calf atrial tissue up to $6 \mathrm{~mm}$ thick, which was the maximal thickness of measured adult human LA.

In comparison, animal studies with different energy sources have reported a wide range of lesion thickness in beating-heart models (Table 1). ${ }^{8-14}$ Cryoablation has produced transmural lesions in $25 \%$ to $100 \%$ of samples in beating-heart models with a mean LA thickness of $2.0 \pm 0.3 \mathrm{~mm} .{ }^{8}$ Transmularity with microwave ablation has only been achieved in $20 \%$ to $46 \%$ of samples in beating-heart animal models with a mean LA thickness of $2.62 \pm 1.31 \mathrm{~mm}^{9-11}$ Only 1 study has reported transmularity with a laser energy source for surgical AF in beating hearts, which showed all lesions to be transmural in dogs, with an average tissue thickness of $3.62 \pm 1.50 \mathrm{~mm}$ (range, $0.95-7.06 \mathrm{~mm}$ ). ${ }^{12}$ Bipolar radiofrequency clamp devices have been shown to create transmural lesions in $92 \%$ to $100 \%$ of samples in beating-heart animal models. ${ }^{13,14}$ However, the average tissue thickness was $4.2 \pm 0.1 \mathrm{~mm}$ in the swine model ${ }^{13}$ and $1.9 \pm 1.1 \mathrm{~mm}$ in the sheep model. ${ }^{14}$ In this study we tested the HIFU product in an animal model with much greater LA thickness relative to other beating-heart models and with only a single application, yet the experimental lesions in this study were deeper than those observed in the other models.
In our analysis of human LA thickness, we found that the average human LA measures $3.7 \mathrm{~mm}$ (range, $1.2-6 \mathrm{~mm}$ ). Our results are similar to those of other anatomic studies aimed to define the human LA anatomy to provide a firm background for the development of AF ablation techniques. Cabrera and coworkers ${ }^{15}$ reported a mean LA thickness of $2.8 \pm 1.1 \mathrm{~mm}$ (range, 1.5-4.2 $\mathrm{mm}$ ) between the orifices of the left pulmonary veins and the os of the LA appendage in a total of $22 \mathrm{hu}$ man hearts. Ho and colleagues ${ }^{16}$ found a mean LA thickness of $3.7 \pm 0.6 \mathrm{~mm}$ (range, $2.9-4.5 \mathrm{~mm}$ ) at the venoatrial junction of the left superior pulmonary vein in a total of 26 human hearts. Sánchez-Quintana and associates ${ }^{17}$ showed a mean LA thickness of $6.5 \pm 2.5 \mathrm{~mm}$ (range, $2.8-12 \mathrm{~mm}$ ) at the middle of the posterior atrial wall in a total of 15 cadavers. These results suggest that the LA thickness of the canine, swine, and sheep models in previous reports falls short of maximal adult human LA thickness. Thus these models might not be ideal for testing transmurality. In contrast, the calf model provides a tissue thickness much greater than human LA, as demonstrated by our findings.

Another advantage of the Epicor LP HIFU system is that epicardial fat dissection is not necessary to achieve transmural ablation. The average amount of adipose tissue in the 9 animals included in this study was $3.10 \mathrm{~mm}$ (range, $0-16 \mathrm{~mm}$ ). As an example, a lesion of $20.2 \mathrm{~mm}$ total thickness with $16 \mathrm{~mm}$ of adipose tissue had a gap of only 0.55 $\mathrm{mm}$ of nonablated tissue after a single application of the Epicor UltraCinch LP device, which demonstrates the efficacy of HIFU to penetrate through fat. In contrast, Turek and coworkers ${ }^{18}$ reported that microwave energy has diminished penetration through adipose tissue. Assessment of adipose tissue penetration by using other energy sources (cryoablation, radiofrequency ablation, and laser ablation) has not been reported.

Some of the factors that might influence the depth of the ablation achieved with alternative energy sources are anatomy, tissue composition, device sizing and position, and saline flow rates. It did not appear that the amount of adipose tissue present on the target LA significantly contributed to the depth of the ablation in this model. However, the shape of the target tissue and the orientation of the HIFU beam seem to play an important role in obtaining transmurality.

TABLE 1. Transmurality in beating-heart models

\begin{tabular}{llccc}
\hline \multicolumn{1}{c}{ Study } & \multicolumn{1}{c}{ Energy source } & Animal model & Mean LA thickness (mm) & Transmurality (\%) \\
\hline Doll and coworkers, ${ }^{8}$ 2003 & Cryoablation & Dog & $2.0 \pm 0.3$ & 96 \\
Van Brakel and coworkers, ${ }^{9} 2004$ & Epicardial microwave & Dog & NS & 33 \\
Melby and coworkers, ${ }^{10} 2006$ & Epicardial microwave & Pig & $2.62 \pm 1.31$ & 46 \\
Gaynor and coworkers, ${ }^{11} 2006$ & Epicardial microwave & Pig & $2.88 \pm 0.4$ & 20 \\
Williams and coworkers, ${ }^{12} 2006$ & Laser & Dog & $3.62 \pm 1.5$ & 100 \\
Melby and coworkers, ${ }^{13} 2006$ & Bipolar RF & Pig & $4.2 \pm 0.1$ & 100 \\
Bugge and coworkers, ${ }^{14} 2005$ & Bipolar RF & Sheep & $1.9 \pm 1.1$ & 92 \\
Villamizar and coworkers, 2010 & HIFU & Calf & $9.10 \pm 2.6$ & 84 \\
\hline
\end{tabular}

$L A$, Left atrial; $N S$, nonspecified; $R F$, radiofrequency; $H I F U$, high-intensity focused ultrasound. 
All animals underwent ablation with either a 7- or 8-cell Epicor UltraCinch LP device. Because each cell measures $1.0 \times 1.5 \mathrm{~cm}$, it is possible to create a significant gap interface between the cell surface and the epicardium when oversizing the circumference around the pulmonary vein orifices. On the other hand, undersizing might inhibit saline flow to cool off the Epicor UltraCinch LP cells and maintain their integrity throughout the ablation cycle. Thus appropriate sizing is important when using this epicardial technology.

Another end point of this study was to determine the presence of vascular injury and thrombogenic complications in areas where the Epicor LP HIFU system is applied. No thrombogenic complications were appreciated with the use of the Epicor LP HIFU system in this study. In comparison, unipolar radiofrequency ablation has been associated with thromboembolic complications, ${ }^{19}$ which appear to be absent with the use of bipolar radiofrequency devices. ${ }^{20}$ There have also been reports of coronary artery stenosis with microwave technology. ${ }^{21}$ Although experience has shown that cryothermal energy appears to have no permanent effects on valvular tissue or the coronary sinus, experimental studies have shown late minimal hyperplasia of coronary arteries. ${ }^{22-24}$ There are no reports about the effect of laser ablation on the coronary vessels. The effect of HIFU ablation on the small vessels found within the HIFU beams appeared to be less destructive than has been observed with other energy sources, such as microwave ablation. ${ }^{18}$ The ability of HIFU to ablate tissue surrounding the coronary arteries without damaging the arteries themselves has been attributed to the protective cooling effect provided by the high blood flow through the coronary arteries and the absence of acoustic heating of the blood. ${ }^{25}$

This study has some limitations that deserve discussion. First, it uses a calf model to investigate the ablative characteristics of a device designed to ablate human cardiac tissue. It is unclear how healthy calf atrial tissue compares with diseased human atria in patients with AF. Second, this study represents an acute examination of the injured tissue; some cells that appear dead might resurrect, and cells that appear viable might die later. Anatomy or dimensions of the scar at 1 to 3 months might appear different, and therefore we are planning more chronic studies. Third, conduction block was not evaluated. The calf LA thickness was considerably greater than the human LA thickness, and therefore gaps were anticipated. Also, calves have a left superior vena cava that traverses the site of the HIFU lesion, resulting in greater total tissue thickness and preventing transmurality at this site. Finally, acute conduction block might not correlate with late conduction block.

Despite these limitations, some assumptions could be made from the observed results. The average calf LA thickness in this study was $9.10 \mathrm{~mm}$, and the range was between 2.5 and $20.1 \mathrm{~mm}$. In contrast, the average LA in 18 human hearts ranged between 1.2 and $6 \mathrm{~mm}$, with a mean of 3.7 $\mathrm{mm}$. HIFU ablation consistently produced a $100 \%$ transmural lesion in LA tissue thickness up to $6 \mathrm{~mm}$. Human LA thickness is generally less than $6 \mathrm{~mm}$, and in this range HIFU ablation should achieve transmurality.

We thank Tom Eby and Jennifer Teng for their technical assistance and contributions throughout the course of this protocol.

\section{References}

1. Feinberg WM, Blackshear JL, Laupacis A, Kronmal R, Hart RG. Prevalence, age distribution and gender of patients with atrial fibrillation: analysis and implications. Arch Intern Med. 1995;155:469-73.

2. Prasad SM, Maniar HS, Camillo CJ, Schuessler RB, Boineau JP, Sundt TM III, et al. The Cox maze III procedure for atrial fibrillation: long-term efficacy in patients undergoing lone versus concomitant procedures. J Thorac Cardiovasc Surg. 2003;126:1822-8.

3. Haissaguerre M, Jais P, Shah DC, Takahashi A, Hocini M, Quiniou G, et al. Spontaneous initiation of atrial fibrillation by ectopic beats originating in the pulmonary veins. N Engl J Med. 1998;339:659-66.

4. Ninet J, Roques X, Seitelberger R, Deville C, Pomar JL, Robin J, et al. Surgical ablation of atrial fibrillation with off-pump, epicardial, high-intensity focused ultrasound: results of a multicenter trial. J Thorac Cardiovasc Surg. 2005;130: 803-9.

5. Groh MA, Binns OA, Burton HG, Ely SW, Johnson AM. Ultrasonic cardiac ablation for atrial fibrillation during concomitant cardiac surgery: long-term clinical outcomes. Ann Thorac Surg. 2007;84:1978-83.

6. Melby SJ, Lee AM, Schuessler RB, Damiano RJ. The effect of residual gaps in ablation lines for the treatment of atrial fibrillation. Heart Rhythm. 2005;2:S15.

7. Comas GM, Imren Y, Williams MR. An overview of energy sources in clinical use for the ablation of atrial fibrillation. Semin Thorac Cardiovasc Surg. 2007; 19:16-24

8. Doll N, Kornherr P, Aupperle H, Fabricius AM, Kiaii B, Ullmann C, et al. Epicardial treatment of atrial fibrillation using cryoablation in an acute off-pump sheep model. Thorac Cardiovasc Surg. 2003;51:267-73.

9. van Brakel TJ, Bolotin G, Salleng KJ, Nifong LW, Allessie MA, Chitwood WR Jr, et al. Evaluation of epicardial microwave ablation lesions: histology versus electrophysiology. Ann Thorac Surg. 2004;78:1397-402.

10. Melby SJ, Zierer A, Kaiser SP, Schuessler RB, Damiano RJ Jr. Epicardial microwave ablation on the beating heart for atrial fibrillation: the dependency of lesion depth on cardiac output. J Thorac Cardiovasc Surg. 2006;132:355-60.

11. Gaynor SL, Byrd GD, Diodato MD, Ishii Y, Lee AM, Prasad SM, et al. Microwave ablation for atrial fibrillation: dose-response curves in the cardioplegiaarrested and beating heart. Ann Thorac Surg. 2006;81:72.

12. Williams MR, Casher JM, Russo MJ, Hong KN, Argenziano M, Oz MC. Laser energy source in surgical atrial fibrillation ablation: preclinical experience. Ann Thorac Surg. 2006;82:2260-4.

13. Melby SJ, Gaynor SL, Lubahn JG. Efficacy and safety of right and left atrial ablations on the beating heart with irrigated bipolar radiofrequency energy: a long-term animal study. J Thorac Cardiovasc Surg. 2006;132:853-60.

14. Bugge E, Nicholson IA, Thomas SP. Comparison of bipolar and unipolar radiofrequency ablation in an in vivo experimental model. Eur J Cardiothorac Surg. 2005;28:76-82.

15. Cabrera JA, Ho SY, Climent V, Sánchez-Quintana D. The architecture of the left lateral atrial wall: a particular anatomic region with implications for ablation of atrial fibrillation. Eur Heart J. 2008;29:356-62.

16. Ho SY, Sanchez-Quintana D, Cabrera JA, Anderson RH. Anatomy of the left atrium: implications for radiofrequency ablation of atrial fibrillation. J Cardiovasc Electrophysiol. 1999;10:1525-33.

17. Sánchez-Quintana D, Cabrera JA, Climent V, Farré J, Mendonça MC, Ho SY. Anatomic relations between the esophagus and left atrium and relevance for ablation of atrial fibrillation. Circulation. 2005;112:1400-5.

18. Turek JW, Dibernardo LR, Lodge AJ, Lin SS, Davis RD, Milano CA, et al. Histopathology and transmurality of acute microwave lesions on the beating human atrium. Interact Cardiovasc Thorac Surg. 2006;5:202-6.

19. Epstein MR, Knapp LD, Martindill M, Lulu JA, Triedman JK, Calkins H, et al. Embolic complications associated with radiofrequency ablation. Am J Cardiol. 1996;77:655-8. 
20. Lall SC, Damiano RJ. Surgical ablation devices for atrial fibrillation. J Interv Card Electrophysiol. 2007;20:73-82.

21. Manasse E, Medici D, Ghiselli S, Ornaghi D, Gallotti R. Left main coronary arterial lesion after microwave epicardial ablation. Ann Thorac Surg. 2003;76: 276-7.

22. Manasse E, Colombo P, Roncalli M, Galloti R. Myocardial acute and chronic histological modifications induced by cryoablation. Eur J Cardiothorac Surg. 2000;17:339-40.
23. Mikat EM, Hackel DB, Harrison L, Gallagher JJ, Wallace AG. Reaction of the myocardium and coronary arteries to cryosurgery. Lab Invest. 1977;37:632-41.

24. Holman WL, Ikeshita M, Ungerleider RM, Smith PK, Ideker RE, Cox JL. Cryosurgery for cardiac arrhythmias: acute and chronic effects on coronary arteries. Am J Cardiol. 1983;51:149-55.

25. Curra F, Mourad P, Crum LA. High intensity focused ultrasound and tissue heating: the effect of nonlinear sound propagation and vessel presence. Proc IEEE Ultrasonics Symp. 1998;2:1419-22.

Access to The Journal of Thoracic and Cardiovascular Surgery Online is reserved for print subscribers!

Full-text access to The Journal of Thoracic and Cardiovascular Surgery Online is available for all print subscribers. To activate your individual online subscription, please visit The Journal of Thoracic and Cardiovascular Surgery Online, point your browser to http://www.mosby.com/itcvs, follow the prompts to activate your online access, and follow the instructions. To activate your account, you will need your subscriber account number, which you can find on your mailing label (note: the number of digits in your subscriber account number varies from 6 to 10 ). See the example below in which the subscriber account number has been circled:

\section{Sample mailing label}

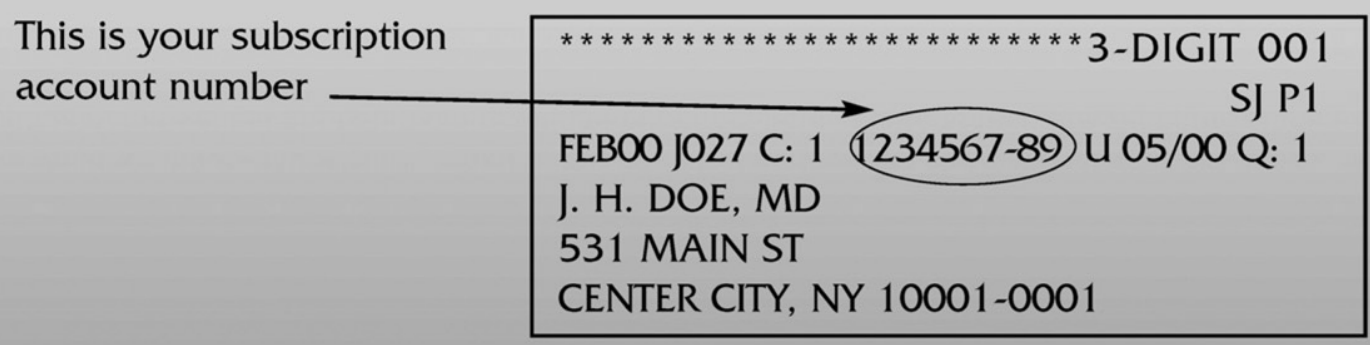

Personal subscriptions to The Journal of Thoracic and Cardiovascular Surgery Online are for individual use only and may not be transferred. Use of The Journal of Thoracic and Cardiovascular Surgery Online is subject to agreement to the terms and conditions as indicated online. 


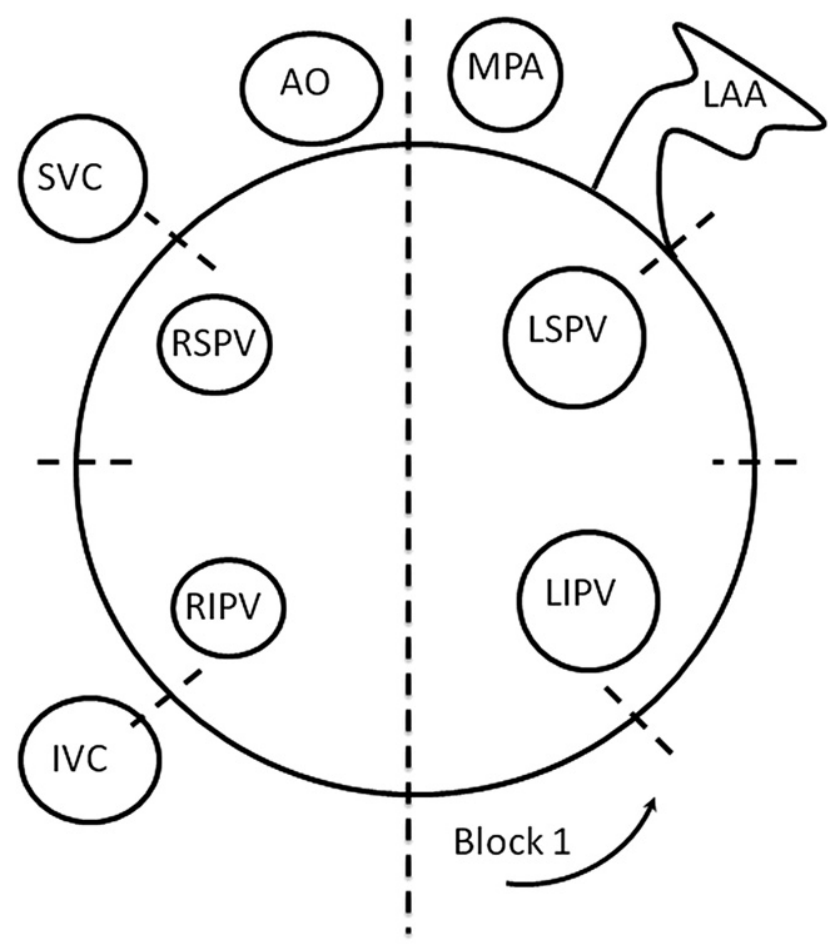

FIGURE E1. Representation of how the fixed left atrium was divided into 8 sections (blocks) along the high-intensity focused ultrasound lesion to obtain histology slides. Ao, Aorta; $I V C$, inferior vena cava; $L A A$, left atrial appendage; $L I P V$, left inferior pulmonary vein; $L S P V$, left superior pulmonary vein; $M P A$, main pulmonary artery; $R I P V$, right inferior pulmonary vein; $R S P V$, right superior pulmonary vein; $S V C$, superior vena cava.

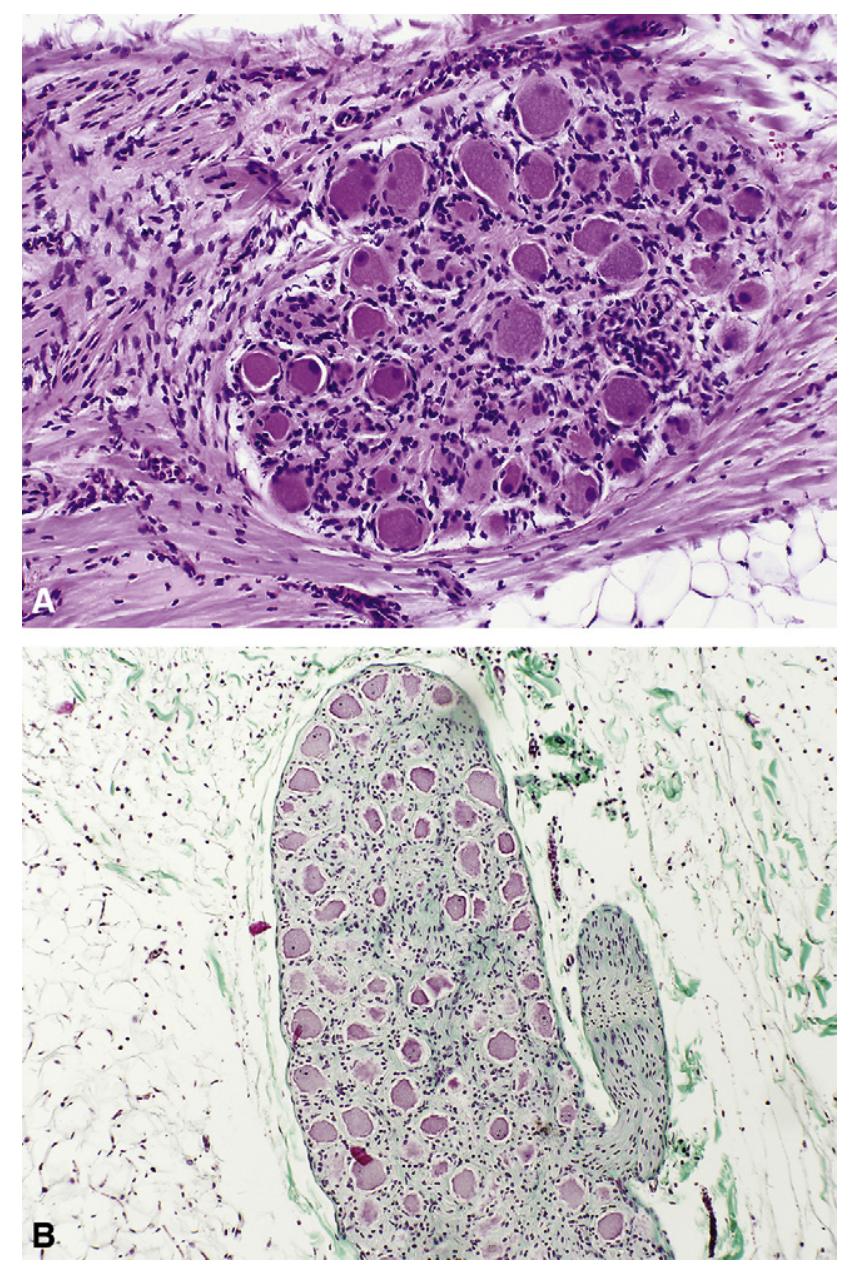

FIGURE E3. A, Irreversibly injured nerve bundle identified within the high-intensity focused ultrasound beam caused by the Epicor UltraCinch LP (hematoxylin and eosin stain). B, Ganglionic plexi ablated by the Epicor UltraWand LP (Masson trichrome stain).

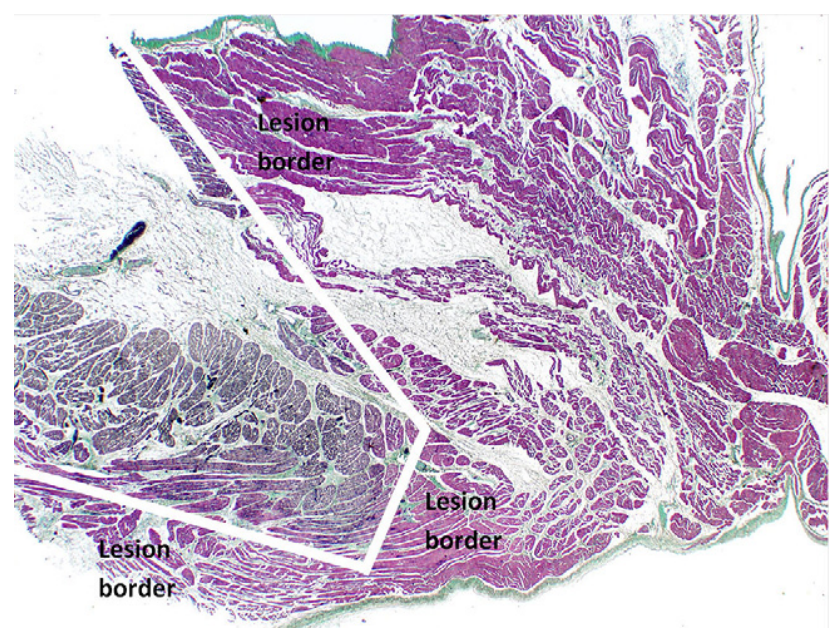

FIGURE E2. Oblique lesion presumably related to the shape of the target tissue and the orientation of the high-intensity focused ultrasound lesion. 